\title{
A classificação e o acesso à informação em Moçambique
}

\author{
Classification and access to information in Mozambique
}

\author{
Gildo Carlos Macie \\ Licenciado em Arquivística pela Escola de Comunicação e Artes da Universidade Eduardo Mondlane, \\ Moçambique. \\ Assistente do Departamento de Ciência da Informação da Escola de Comunicação e Artes da Universidade \\ Eduardo Mondlane, Moçambique. \\ E-mail: gildo.macie6@gmail.com \\ https://orcid.org/0000-0003-4800-6551 \\ Cecília Preciosa Cabsela \\ Licenciada em Arquivística pela Escola de Comunicação e Artes da Universidade Eduardo Mondlane, \\ Moçambique. \\ E-mail: preciosacaroo@yahoo.com \\ https://orcid.org/0000-0002-2216-5792
}

\author{
Rafael Simone Nharreluga \\ Doutor em História, Política e Bens Culturais pelo CPDOC/FGV, Brasil. \\ Assistente do Departamento de Ciência da Informação da Escola de Comunicação e Artes da Universidade \\ Eduardo Mondlane, Moçambique. \\ E-mail: rafalluga@yahoo.com.br \\ https://orcid.org/0000-0002-3258-4413
}

\section{Resumo}

Este artigo, de natureza qualitativa em sua abordagem, tem como objetivo analisar a situação arquivística em Moçambique, a partir do cruzamento da prática arquivística exercida nas instituições da administração pública ênfase na classificação arquivística - com a classificação das informações referida no âmbito da legislação sobre o direito à informação, com destaque para a Lei do Direito à Informação e demais instrumentos legais com ela conjugados, contrapondo o sigilo em relação ao acesso à informação. Buscou-se um referencial teórico, cujo desenvolvimento baseou-se no conceito de gestão de documentos para extrair a ideia de organização de documentos, numa articulação com a matriz histórica do acesso à informação que relativiza o sigilo. Constatou-se o desenquadramento da prática arquivística em curso nas instituições da administração pública, em decorrência da falta de integração da dimensão profissional da arquivística nas diversas atividades e do sigilo impregnado na legislação sobre o direito à informação ou a ela relacionada. Conclui-se que somente a introdução de medidas de redução ou superação do caráter absoluto do sigilo em relação ao acesso à informação e de profissionalização e regulamentação da área dos arquivos em Moçambique poderá ultrapassar o problema.

Palavras-chaves: Moçambique. Classificação arquivística. Direito à informação.

\begin{abstract}
This article, of a qualitative nature in its approach, aims to analyse the archival situation in Mozambique, based on the crossing of the archival practice exercised in the public administration institutions - emphasis on archival classification - with the classification of the information referred to in the scope of the legislation on the right to information, with emphasis on the Right to Information Law and other legal instruments combined with it, opposing secrecy in relation to access to information. A theoretical reference was sought, the development of which was based on the concept of Records management to extract the idea of document organisation, in articulation with the historical matrix of access to information that relativises secrecy. It was noted that the archival practice in progress in public administration institutions is not in line with the professional dimension of archival science in the various activities and the secrecy impregnated in the legislation concerning the right to information or other related to it. It is concluded that only the introduction of measures to reduce or overcome the absolute nature of secrecy in relation to access to information and the professionalisation and regulation of the area of archives in Mozambique can overcome the problem.
\end{abstract}

Keywords: Mozambique. Archival Classification. Right to information.

InCID: R. Ci. Inf. e Doc., Ribeirão Preto, v. 11, n. 2, p. 4-22, set. 2020/fev. 2021.

DOI: 10.11606/issn.2178-2075.v11i2p4-22 


\section{Introdução}

Ao concebermos a classificação como uma atividade básica na prática arquivística e para o alcance da finalidade dos arquivos, numa altura em que muito se discute sobre o direito à informação em Moçambique, pretendemos mapear o cenário arquivístico nacional, tendo como ponto de partida, a prática arquivística em curso nas instituições da administração pública, a Lei do Direito à Informação de Moçambique, aprovada em 2014, através da Lei no 34/2014, de 31 de Dezembro, e o respectivo Regulamento, aprovado pelo Decreto n. ${ }^{\circ}$ 35/2015, de 31 de Dezembro. Nesse âmbito, buscou-se aferir a concepção da classificação e sua eventual prática profissional na realidade arquivística moçambicana, observando o trabalho desenvolvido em arquivos de quatro instituições públicas, nomeadamente, o Ministério para a Coordenação da Acção Ambiental - hoje Ministério da Terra, Ambiente e Desenvolvimento Rural- ${ }^{-}$o Instituto Nacional de Estatística, a Administração Nacional de Estradas e a Escola de Comunicação e Artes, doravante designadas neste estudo, respectivamente, por MICOA, INE, ANE e ECA.

Ao estudar a classificação de documentos nas instituições públicas moçambicanas enquanto uma dimensão na organização de documentos de arquivo, assim como a concepção do termo "classificação" nos instrumentos legais, este trabalho pretende extrair desses processos, algumas ilações que contribuam para a caracterização do direito à informação em Moçambique e fixar suas tendências, com o objetivo de estimular um debate sobre a situação dos arquivos e do acesso à informação arquivística em neste país.

Baseado numa abordagem qualitativa, o estudo privilegiou a pesquisa bibliográfica para a construção teórica que embasa as inferências, assim como a análise documental na aferição da legislação sobre o direito à informação em Moçambique, recorrendo, igualmente, à observação da prática de classificação nos arquivos das instituições públicas representadas nesta pesquisa pela nossa amostra intencional acima referida. A pesquisa nestas instituições foi realizada no âmbito do trabalho de estágios curriculares I e II, entre 2017 e 2018, integrados no currículo do curso de Licenciatura em Arquivística da Universidade Eduardo Mondlane, por um dos autores deste estudo - enquanto docente e coordenador dos referidos estágios -, envolvendo seus coordenados - discentes em estágio naquelas instituições -, e consistiu na observação da situação dos arquivos e dos trabalhos técnicos arquivísticos - sobretudo de classificação - realizados naquelas instituições, incluindo a análise da aplicação dos instrumentos técnicos de gestão de documentos, num olhar crítico sustentado pelos preceitos arquivísticos previamente estudados e sistematizados. 
Buscamos, nesse sentido, visualizar, por um lado, o processo de classificação arquivística nessas instituições à luz da teoria arquivística inerente à gestão de documentos e, de outro, a classificação das informações, considerando a questão de sigilo em relação ao acesso à informação. Com efeito, a partir do conceito de gestão de documentos, a dimensão arquivística de classificação encontra seu enquadramento teórico, suscitando a polissemia que marca o termo classificação. Nesse âmbito, se de um lado a classificação designa o agrupamento lógico dos documentos baseando-se no assunto contido nesses documentos e no contexto orgânico de produção dos mesmos, tendo em vista a organização e a recuperação da informação, sobretudo, para fins orgânicos, de outro, ela aponta para as restrições legais impostas ao acesso a determinados documentos, de acordo com o assunto que estes ostentam, definindo graus de sigilo enquanto exceções a serem observadas durante um determinado período de tempo legalmente estabelecido e justificado. A variante histórica do acesso à informação encerra este enquadramento, relativizando a questão de sigilo.

\section{Embasamento teórico}

Nesta parte do texto, apresentam-se os elementos conceituais necessários ao entendimento, operando o devido enquadramento teórico da classificação e do acesso à informação. Assim, tomamos neste estudo a classificação arquivística como uma atividade essencial, cujo exercício dentro dos quadros gerais da gestão de documentos conduz ao tratamento, organização, recuperação e uso dos documentos de arquivo, concorrendo para o controle efetivo do ciclo de vida e da circulação da informação nas instituições e, por conseguinte, para o acesso à informação que, por sua vez, consubstanciando a finalidade dos arquivos, habilita o exercício da cidadania. 


\subsection{O conceito de gestão de documentos e seu desdobramento em operações técnicas específicas}

Indolfo (2007, p. 40) recorre às versões do Dicionário de Terminologia Arquivística do Conselho Internacional de Arquivos, para definir a gestão de documentos como a "área da administração geral que procura alcançar economia e eficiência na criação, manutenção, uso e eliminação de documentos, ao longo do seu ciclo de vida" e, ainda, como o campo da gestão responsável pelo controle eficiente e sistemático da criação, manutenção, uso e destinação dos documentos. E Paes (2004, p. 53), citando a Lei Federal brasileira n. ${ }^{\circ}$ 8.159, de 8-1-1991, entende que a gestão de documentos é "o conjunto de procedimentos e operações técnicas referentes à sua produção, tramitação, uso, avaliação e arquivamento em fase corrente e intermediária, visando sua eliminação ou recolhimento para guarda permanente". Esta autora refere ainda que a gestão de documentos compreende três fases básicas que correspondem a produção, a utilização e a destinação.

Paes (2004, p. 54) descreve a primeira fase, a produção, enquanto um ato de "elaboração dos documentos essenciais em decorrência das atividades de um órgão ou setor”, inserindo-a numa visão tanto de optimização da criação dos documentos estritamente necessários ao processo administrativo como de evitar a produção daqueles documentos não essenciais, com vista a diminuir o volume de documentos a serem manuseados, controlados, armazenados e eliminados, e a garantir o uso adequado dos recursos de reprografia e automação (INDOLFO et al., 1995, p. 15).

A fase de utilização

refere-se ao fluxo percorrido pelos documentos, necessário ao cumprimento de sua função administrativa, assim como sua guarda após cessar seu trâmite. Esta fase envolve métodos de controle relacionados às atividades de protocolo e às técnicas específicas para classificação, organização e elaboração de instrumentos de recuperação de informação (INDOLFO et al., 1995, p. 15).

Esta fase, portanto, se dá numa perspectiva, também, de desenvolvimento da gestão de arquivos correntes e intermediários e de implantação de sistemas de informação gerencial, sendo um momento indicado para a realização da classificação no seu sentido que designa o agrupamento de documentos, de acordo com os assuntos que ostentam.

E por fim, a terceira fase da gestão de documentos, a destinação, "envolve as atividades de análise, seleção e fixação de prazos de guarda dos documentos, ou seja, implica em decidir" 
quais os documentos a serem destruídos e quais serão preservados provisoriamente ou de forma permanente, mediante o seu valor (INDOLFO et al., 1995, p. 15).

A realização de todas as atividades previstas nas três fases da gestão de documentos se efetiva com base num programa de gestão de documentos, cuja função é operacionalizar esta através do "planejamento, da organização, do controle, da coordenação dos recursos humanos, do espaço físico e dos equipamentos, com o objetivo de aperfeiçoar e simplificar o ciclo documental" (INDOLFO et al., 1995, p. 14).

Tanto o Dicionário de Terminologia Arquivística citado por Indolfo (2007) como Paes (2004), são unânimes em mencionar as atividades de protocolo que compreendem, entre outras operações, a classificação, como parte da gestão de documentos e que concorrem para a elaboração de normas de acesso aos documentos, na fase de utilização.

Rodrigues (2006, p. 103) observa que a gestão de documentos não surgiu da prática ou teoria dos arquivos, mas por uma necessidade da administração pública, principalmente em meados do séc. XX, logo após a Segunda Guerra Mundial. Na mesma linha de pensamento, Paes (2004) acrescenta que foi o advento da ciência e da tecnologia que favoreceu o crescimento exponencial da produção de documentos, cujo efeito foi a superação da capacidade de controle e organização das instituições, obrigando as instituições a buscarem novas soluções para gerir as grandes massas documentais por elas acumuladas.

Jardim (1987) vai ainda mais longe para indicar os primórdios da gestão de documentos, ao referir que embora a concepção teórica e aplicabilidade da gestão de documentos tenha se desenvolvido após a Segunda Guerra Mundial, a partir dos Estados Unidos da América (EUA) e Canadá, passando mais tarde para países europeus, asiáticos e africanos, esta possuía raízes já nos finais do século XIX, em função dos problemas então detetados nas administrações públicas dos EUA e Canadá, no que se refere ao uso e guarda de documentos.

O mesmo autor refere ainda que, a aplicação dos princípios da administração científica para a solução dos problemas documentais teria gerado os princípios da gestão de documentos, os quais resultaram, sobretudo, da necessidade de se racionalizar e modernizar as administrações. Nesse âmbito, a gestão de documentos teria contribuído para o desenvolvimento das funções arquivísticas de diversas maneiras, 
ao garantir que as políticas e atividades dos governos fossem documentadas adequadamente; ao garantir que menor número de documentos inúteis e transitórios fossem reunidos a documentos de valor permanente; ao garantir a melhor organização desses documentos, caso atingissem a fase permanente; ao inibir a eliminação de documentos de valor permanente; ao garantir a definição de forma criteriosa da parcela de documentos que constituíssem o patrimônio arquivístico de um país, ou seja, de 2 a 5\% da massa documental produzida, segundo a Unesco (JARDIM, 1987, p. 36).

Portanto, é no quadro do conceito de gestão de documentos que surge a classificação arquivística como uma das suas operações técnicas, inserida dentro das atividades de protocolo, numa perspectiva de organização de documentos que antecipa e assegura a realização das atividades subsequentes de arquivamento de documentos em arquivos correntes e intermediários.

Suscitada na segunda fase da gestão de documentos, a de utilização, a classificação arquivística de documentos é entendida por Indolfo como

o estabelecimento de classes nas quais se identificam as funções e as atividades exercidas, e as unidades documentárias a serem classificadas, permitindo a visibilidade de uma relação orgânica entre uma e outra, determinando agrupamentos e a representação, sob a forma de hierarquia, do esquema de classificação proposto (INDOLFO, 2007, p. 45).

Antes, Indolfo (2007, p. 45) ensina que "a tarefa de classificação exige o conhecimento da estrutura organizacional da administração produtora dos documentos e das necessidades de utilização dos documentos produzidos por esses administradores”. Nesse contexto, o exercício da atividade classificatória afigura-se primordial para o entendimento do documento arquivístico dentro do seu quadro geral de produção, fora do qual, o mesmo não pode ser compreendido e jamais poderá configurar o uso pleno da informação contida nos documentos.

Outro aspecto de vital importância em relação à classificação em Indolfo refere que a ação de classificar constitui uma operação intelectual que consiste em "dividir em classes ou grupos, segundo as diferenças e semelhanças, um conjunto de conceitos, categorias, metodicamente distribuídos ou dispostos" (INDOLFO, 2007, p. 48). Esta visão sugere a classificação como um processo mental, habitual e orientado à organização e recuperação da informação que, para a sua realização, exige a aplicação de métodos científicos orientados pelas técnicas e princípios arquivísticos. Ou seja, a classificação arquivística insere uma reflexão, análise e entendimento do conteúdo do documento dentro do seu conjunto, salvaguardando o caráter orgânico e peculiar dos documentos de arquivo.

Bernardes e Delatorre (2008, p. 15) chamam atenção para o fato de que "a classificação de um documento de arquivo exige uma rigorosa análise documental que deve partir, antes de 
qualquer coisa, da definição do objeto a ser analisado: o documento de arquivo". Nesse âmbito, considerando todo o escopo conceitual da ação de classificação, significa que a mesma deve ser realizada por funcionários profissionalmente qualificados e previamente orientados para garantir a materialização da relação intrínseca existente entre os documentos de arquivo. Há que considerar, nesse sentido, tanto o momento de sua planificação que resulta na elaboração do plano de classificação enquanto um instrumento que, segundo Rodrigues (2006), permite a enunciação lógica e hierárquica de um conjunto de documentos produzidos por um órgão, quanto da sua operacionalização através deste instrumento básico de gestão de documentos. Assim concebida, a classificação arquivística constitui um dos requisitos fundamentais para a realização da avaliação e seleção de documentos e demais ações inerentes ao trabalho arquivístico, culminando com a eficácia e eficiência na recuperação da informação para diversos fins.

É nesta esfera que se propõe pensar e discutir o acesso à informação em sua perspectiva arquivística em que, no nosso entender, se configura a sua génese. De fato, ao abordarmos este tema, decidimos olhar para a informação como um recurso estratégico, cuja gestão, além de proporcionar eficiência institucional e responder a questões práticas a todos os níveis da administração pública, contribui para a melhoria do desempenho institucional, apontando níveis de transparência administrativa. Portanto, ao partirmos do conceito de gestão de documentos buscávamos alinhar a noção de classificação arquivística e, deste modo, traçar a sua relação com o acesso à informação.

Antes de abordarmos a questão de acesso à informação, é importante situar, ainda que de forma breve, a outra acepção da classificação, a classificação da informação, aquela que, pela natureza dos assuntos, classifica as informações como ostensivas ou sigilosas, numa perspectiva que estabelece categorias de documentos, de um lado, de acesso livre e imediato após a sua produção e, de outro, sistematicamente excluídos do direito de livre e imediato acesso. Assim, a classificação de ostensiva é dada aos documentos sem qualquer restrição ao acesso. Já a classificação de sigilosa recai sobre todos os documentos que, pela natureza de seu conteúdo, requerem medidas especiais de acesso, podendo serem classificados como ultrasecreto, secreto, confidencial e reservado. Para Paes (2004), os documentos com a classificação de sigilosa, pela importância salutar de que se revestem, deviam ser objeto de uma legislação própria, como se pode entender, não apenas para salvaguardar a questão de sigilo, mas também para justificar essa questão. Mais do que isso, uma lei de direito à informação deve transpor a 
perspectiva de sigilo e estabelecer critérios voltados a identificar a informação de domínio público enquanto objeto de acesso.

\subsection{Matriz histórica do acesso à informação: a relativização do sigilo}

A acessibilidade aos documentos por parte do cidadão comum era bastante controlada desde os tempos clássicos. Na verdade, a acessibilidade aos documentos sempre foi um privilégio para aqueles que detêm o poder (SILVA et al., 1998).

Entretanto, Lima et al. (2012) observam a gênese do acesso à informação, cujos contornos históricos têm relativizado o sigilo nos seguintes termos:

\footnotetext{
Embora a história do direito e acesso à informação não seja linear, no decurso do tempo vemos que, em 1766, na Suécia os cidadãos reivindicavam do Estado, o acesso à informação, sobretudo a de foro administrativo. O passo seguinte deu-o, em 1781, a República de Veneza, para, pouco tempo depois, em 26 de agosto de 1789, a França consagrar o direito e acesso à informação (LIMA et al., 2012 p. 7).
}

Suscitado na Declaração dos Direitos do Homem e do Cidadão (de 1789), na perspectiva de livre comunicação de ideias e opiniões (artigo 10), e considerado na mesma Declaração como "um dos mais preciosos direitos do Homem" (artigo11), o acesso à informação encontra sua forma mais atual na Declaração Universal dos Direitos Humanos (ORGANIZAÇÃO DAS NAÇÕES UNIDAS, 1948) que, no seu artigo 19, afirma "Todo ser humano tem direito à liberdade de opinião e expressão; esse direito inclui a liberdade de, sem interferência, ter opiniões e de procurar, receber e transmitir informações e idéias por quaisquer meios e independentemente de fronteiras".

Portanto, é nesta perspectiva em que o cidadão tem o direito de procurar e receber informações produzidas pelas diversas instituições do Estado, que interessa, neste estudo, a noção de acesso à informação, buscando aferir o grau de sua realização efetiva em Moçambique tanto no âmbito do processo de organização de documentos que toma a classificação arquivística como uma das suas operações técnicas mais relevantes, quanto da legislação sobre o direito à informação neste país que define os graus de sigilo dos documentos de arquivo.

Esta breve alusão histórica mostrou-se necessária para inserir um traçado assente na evolução do conceito de acesso à informação ao longo dos tempos e sua configuração, considerando o usufruto dos direitos de cidadania em cada momento, sem descurar do papel dos governos enquanto servidores dos cidadãos e, estes, como controladores daqueles e dos 
seus respectivos atos, concorrendo para a materialização e participação na construção de um Estado de direito democrático. Ora, o Estado moçambicano sempre se caracterizou pelo secretismo e "ignorância" no tocante à garantia do acesso à informação, fato que pode ser facilmente observado a partir dos textos constitucionais, da própria Lei do Direito à Informação, dos vários programas quinquenais do Governo e da forma de ser e estar da/na administração pública.

\section{Resultados e discussão}

O cenário arquivístico moçambicano mapeado neste estudo é representado por arquivos de quatro instituições públicas enquanto lugar de práticas arquivísticas - sobretudo de classificação em sua dimensão de organização de documentos - e pela legislação sobre o direito à informação em Moçambique - que insere a classificação da informação, fundamentando a atribuição de graus de sigilo -, sendo analisado à luz do referencial acima referido. Nesse sentido, passamos a apresentar os resultados da observação feita junto àquelas instituições, discutindo as práticas vivenciadas, numa perspectiva de visualização do grau de organização dos documentos e do acesso à informação.

\subsection{A prática arquivística moçambicana e seus contornos na organização dos arquivos}

O primeiro aspecto que ressalta em todas as instituições observadas é a inexistência de arquivos enquanto unidades orgânicas instituídas. Dos trabalhos de arquivo em curso nestas instituições nenhum deles se enquadra perfeitamente dentro do conceito de gestão de documentos. Munidas de instrumentos de gestão de documentos - Plano de classificação de atividades-meio e Tabela de temporalidade de atividades-meio -, instituídos em 2007 no âmbito do Sistema Nacional de Arquivos do Estado (SNAE), contudo, a aplicação desses instrumentos constitui um caos, na medida em que não decorre no âmbito dos procedimentos preconizados pela gestão de documentos. Todas as atividades relacionadas à organização de documentos de arquivo nestas instituições refletem uma intervenção sobre massas documentais acumuladas. Faltam rotinas sistematizadas que traduzam atividades de protocolo e de arquivamento de documentos enquadradas num programa de gestão de documentos. Embora anunciados pelo discurso dos respectivos atores, porém, não é possível contemplar a concepção de arquivos correntes e intermediário nestas instituições. Os arquivos nestas instituições traduzem-se tão 
somente em conjuntos de documentos que, a olho nu, parecem estar organizados somente porque estão em caixas.

Foi observada a realização de ações de capacitação a servidores públicos, pelo Centro Nacional de Documentação e Informação de Moçambique (CEDIMO) - uma instituição, segundo Nharreluga (2014), não propriamente arquivística, mas estratégica que, mesmo desprovida de conhecimento técnico arquivístico, representa a hegemonia governamental na área dos arquivos em sua ascensão repentina nesta área a partir dos anos 2000 -, em matérias de classificação arquivística, envolvendo funcionários e chefes de secretarias das instituições públicas. Contudo, tais ações não se traduzem em sucesso em si mesmas e na perspectiva do acesso à informação, devido à sua concepção e implementação fora de âmbito profissional. Como indica Nharreluga (2006, p. 9) para o caso moçambicano, "o caos informacional que assola a administração pública, em alguns casos, não resulta da falta de conhecimento técnicoprofissional da informação, mas da necessidade de manutenção de estratégias de poder e de interesses patrimonialistas e corporativistas".

Para elucidar, Nharreluga (2006) avança com o exemplo do processo de implementação da primeira versão do sistema denominado "Sistema Nacional de Arquivos" (SNA), de 1992, indicando fracassos e resistências no seio dos diferentes atores nele envolvidos. Esta debilidade arquivística moçambicana fica ainda mais visível nas duas versões do SNAE, de 2007 e 2018.

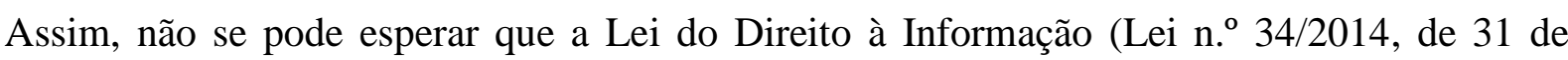
Dezembro) por si só venha garantir o acesso à informação, num contexto em que as atividades arquivísticas continuam a reboque da política sem incorporar a sua dimensão profissional. Como ensina ainda Nharreluga (2006, p. 9), vão se "avolumando as discrepâncias em relação à informação governamental em Moçambique, quer em termos de seus pressupostos políticoideológicos, quer no campo técnico-científico voltado para a gestão de recursos e processos técnicos de informação".

Além de graves problemas provenientes da não institucionalização dos arquivos ou de setores de gestão de documentos nas instituições públicas, constatou-se a falta de programas de gestão de documentos e de um exercício reflexivo orientado pela análise crítica. Resulta daí que os arquivos da administração pública moçambicana sejam caraterizados, entre outros, por documentos sem classificação arquivística ou mal classificados;

O Manual de Procedimentos do SNAE (CENTRO NACIONAL DE DOCUMENTAÇÃO E INFORMAÇÃO DE MOÇAMBIQUE, 2009, p. 11), no seu Capitulo 
II sobre a "Aplicação do Plano de Classificação das Atividades-Meio" apresenta as principais operações a serem observadas na execução da classificação como assentes no estudo do documento. Porém, não frisa a necessidade de um exercício reflexivo, crítico e exaustivo com vista à atribuição correta dos códigos. O mesmo instrumento orienta que a aplicação do código de classificação de documentos é da responsabilidade de funcionários treinados, ao que apuramos que essas ações de treinamento são levadas a cabo, igualmente, por funcionários do CEDIMO em cujo quadro de pessoal, não consta nenhum funcionário com curso superior em arquivos.

Durante a pesquisa, um total de oito funcionários - dois para cada instituição -, que passaram por pelo menos uma das referidas ações de capacitação em matérias de classificação arquivística, foram acompanhados em sua prática de classificação, tendo verificado que apenas dois executam a classificação (aplicação do plano de classificação) de forma correta, enquanto que os outros seis a executam erradamente. Em geral, todos os funcionários envolvidos revelaram fraca capacidade na análise e interpretação dos conteúdos dos documentos e na tradução de assuntos em conceitos. Conforme Padilha e Spudeit (2014) um “documento mal classificado, é um documento perdido" e, deste modo, a avaliar pelo cenário que temos vindo a descrever, os arquivos em Moçambique padecem de práticas arquivísticas nocivas à organização dos arquivos. 


\subsection{A dimensão da legislação na organização de arquivos em Moçambique}

Considerando a área de arquivos em Moçambique, o conjunto de dispositivos legais decretos 33/92, 36/2007 e 84/2018 e a Resolução 46/2006 - estabelecidos, respectivamente, em 1992, 2007, 2018 e 2006, para suscitar a gestão de documentos neste país não conseguiu até hoje trazer uma resposta efetiva quanto às atividades de classificação, avaliação e destinação de documentos. Referindo-se à legislação da área de arquivos instituída em Moçambique pelo menos até o ano de 2000, Nharreluga (2006) afirma que a mesma teria sido marcadamente periférica em sua concepção, permanecendo durante todo o período de sua vigência a enfrentar dificuldades para a sua implementação. $\mathrm{O}$ mesmo autor se refere ainda à falta de arquivos institucionalizados na estrutura do Estado, destacando o AHM como única referência arquivística no país, porém, com um papel reservado apenas à gestão de arquivos do período colonial.

Com a aprovação do SNAE em 2007 e dos respectivos instrumentos de operacionalização da gestão de documentos a ele ligados - Plano de Classificação, Tabela de Temporalidade das atividades-meio e o Classificador de Informações - suscitou-se uma aparente mudança de rumo nas práticas arquivísticas nacionais. Contudo, a mudança limitouse na concepção de tais instrumentos de gestão de documentos, entretanto, desprovidos de medidas estruturais tendentes a profissionalizar a área. Sem estrutura de arquivos que compreenda uma autoridade nacional dotada de conhecimento arquivístico e de todo o tipo de recursos e meios necessários à governança arquivística em nível nacional torna-se impossível viabilizar a gestão de documentos apenas na base de instrumentos, cujo processo de elaboração também não seguiu parâmetros dignos de recomendação arquivística.

Volvidos 28 anos de implementação do projeto de sistema nacional de arquivos em suas três versões instituídas pelos decretos 33/92, 36/2007 e 84/2018, respectivamente, em 1992, 2007 e 2018, a gestão de documentos em Moçambique ainda não constitui uma realidade. Esta deficiência da não efetividade da gestão de documentos neste país, mesmo após sucessivas leis a respeito, associada à cultura de sigilo que atravessa a situação dos arquivos em Moçambique, resulta como entrave ao desiderato de organização de arquivos e, por conseguinte, de acesso à informação arquivística no país. 


\title{
3.3 A concepção da classificação das informações na legislação sobre o direito à informação: a supremacia do sigilo sobre o acesso à informação
}

No que se refere à classificação das informações em Moçambique, recuamos ao ano de 1979 para resgatar a Lei do Segredo do Estado - Lei no . 12/79, de 12 de dezembro -, cujo objetivo é a proteção do "segredo estatal, relativamente a todos os documentos contendo dados e informações classificados" (artigo 1) nos diversos níveis de sigilo. No preâmbulo, avança,

\begin{abstract}
na sua ação, o inimigo tenta obter informação de carácter secreto para utilizá-la na perpetração de novos crimes e atentados contra o nosso Povo, Partido e Estado. Urge, assim, intensificar o processo de criação de instrumentos legais que permitam consolidar o exercício da ditadura democrática popular.
\end{abstract}

Os documentos referidos nesta lei dividem-se em dois grupos. O primeiro corresponde aos "documentos classificados" - "aqueles que contêm dados ou informações militares, políticas, económicas, comerciais, cientificas, técnicas ou quaisquer outras cuja divulgação ponha em causa, prejudique, contrarie ou perturbe a Segurança do Estado e do Povo, ou a economia nacional" (parágrafo 1 do artigo 4). A classificação dada aos dados ou informações referidas neste grupo varia entre "segredo de Estado, secreto, confidencial e restrito" (artigo 5). Já o segundo grupo corresponde aos "documentos não classificados" - "os que não possuem nenhuma das caraterísticas assinaladas no número anterior" (parágrafo 2 do artigo 4).

Na lei da proteção do segredo estatal (Lei 12/79) está patente a tónica do segredo face ao acesso, que nem se quer é referido. Aliás, ao longo da pesquisa não foi observada nenhuma ação de disponibilização de informação a usuários externos dentro das quatro instituições que formam a nossa amostra. Nesta lei, mais do que nunca, o segredo é a regra e o acesso, uma exceção. Ora, nos parece que este é o modus operandi que ficou impregnado no seio da administração pública moçambicana e, até mesmo, do próprio cidadão que supostamente toma este modus operandi como parte de sua cultura de subserviência, dispensando a crítica a aspectos que ferem os seus direitos e liberdades fundamentais simplesmente porque ele já foi historicamente censurado.

Volvidos 25 anos após a Lei no. 12/79, a questão de direito à informação foi conservada na Constituição da República de Moçambique de 2004, depois de ter sido introduzida pela primeira vez na de 1990. Naquela, o parágrafo um do artigo 48, que versa sobre "Liberdades de expressão e informação", inserido no Capítulo II dos "Direitos, Deveres e Liberdades", afirma que "Todos os cidadãos têm direito à liberdade de expressão, à liberdade de imprensa, bem como o direito à informação". 
Entretanto, observado a partir dos diferentes programas governamentais - sobretudo os quinquenais, de 1990 para os dias atuais -, o direito à informação é concebido com ênfase na imprensa, que conheceu a sua regulamentação nesse âmbito, em 1991, através da Lei 18/91, de 10 de agosto, muito antes da atual Lei do Direito à Informação.

Muitas foram as conquistas no âmbito da Constituição de 2004, como se pode ler no Capítulo sobre a “Administração Pública ...”, em que, o artigo 249 dos "Princípios fundamentais", afirma que a "Administração Pública serve o interesse público e na sua actuação respeita os direitos e liberdades fundamentais dos cidadãos”. Este desiderato constitucional, porém, se esbarra nos procedimentos inerentes à sua implementação. Por exemplo, atendendo e considerando o cenário arquivístico moçambicano que temos vindo a descrever, o respeito pelos direitos e liberdades fundamentais torna-se questionável.

Mais adiante, o artigo 253 dos "Direitos e garantias dos administrados", afirma, no parágrafo nr. 1, que "Os cidadãos têm o direito de serem informados pelos serviços competentes da Administração Pública sempre que requeiram sobre o andamento dos processos em que estejam diretamente interessados nos termos da lei”. Este direito de requerer informação às instituições da administração pública, aqui aludido, e que é concedido ao cidadão, é importante ao lembrar que o acesso à informação implica, mais do que o direito de ser informado, o direito de se informar. Porém, num quadro em que os documentos não se encontram devidamente organizados, este direito constitucional torna-se inviável. Em todo o caso, o princípio seria sair do politicamente correto, em que a administração pública "informa" ao cidadão (administrado) aquilo que convém e nos moldes do interesse da manutenção do poder e do exercício de controle sobre ele (cidadão), e caminhar na direção em que o cidadão tem efetivamente o poder de requerer informação (governamental) para o exercício de seus direitos de cidadania, implicando, deste modo, o controle da administração pública por parte do cidadão.

Numa perspectiva de mudança do cenário, o Conselho de Ministros aprovou, em 2006, a Resolução nr. 46/2006, de 26 de dezembro, acima referida e que estabelece a Estratégia para Gestão de Documentos e Arquivos do Estado. Entre vários aspectos, esta Estratégia, baseada no diagnóstico nele contido, destaca o acesso à informação na administração pública moçambicana e seus problemas. Entre os problemas, aponta por um lado, a ausência de diretrizes, normas e orientações metodológicas e, de outro, a atitude dos funcionários em relação à disponibilização de informação, bem como a acessibilidade dos arquivos, como sendo tendenciosa e predominantemente coberta de algum secretismo, em que o acesso a informação 
e a documentação depende muito mais da vontade e iniciativa individual do funcionário do que de orientações institucionais. Avança ainda e aponta uma possível falta de consciência sobre as implicações negativas da falta de informação, na qualidade do trabalho e, na acessibilidade aos documentos e informação pelos utilizadores.

No ano seguinte à aprovação da referida Estratégia, por conseguinte, foi alterada a primeira versão de sistema (SNA), conforme preconizava a mesma Estratégia, e no seu lugar foi instituída, pelo Decreto $n^{\circ}$. 36/2007, de 27 de Agosto, a nova versão que passou designar-se Sistema Nacional de Arquivos do Estado (SNAE). Ora, o artigo 16 do SNAE sobre "Acesso aos arquivos" refere que, é permitido o acesso aos documentos depositados em arquivos públicos a todos os interessados, salvaguardando-se os princípios que regulam o segredo estatal e a inviolabilidade da vida privada. Ademais, indica que os arquivos de acesso condicionado no roteiro do segredo estatal poderão ser livremente consultados pelos utentes, após a queda do sigilo.

Como se pode depreender, até aqui o sentido de segredo continua muito presente. Enquanto isso, a própria classificação das informações é sempre aliada ao secretismo e não ao acesso.

Segue, nesse âmbito, a Lei $n^{\circ}$. 34/2014, 30 de dezembro de 2014, Lei de Direito à Informação, bem como o respectivo Regulamento aprovado pelo Decreto $\mathrm{n}^{\circ}$. 35/2015, de 31 de dezembro. Mais do que regular o direito à informação, esta lei e o seu regulamento regulam o sigilo. Sobre a classificação arquivística, objetivamente, tanto a Lei do Direito à Informação assim como o seu Regulamento, não mencionam a classificação arquivística e, se nesses instrumentos usa-se esta palavra, seu uso se restringe à questão de atribuição de graus de sigilo, cuja definição encontra sua forma final na Lei 12/79, de 12 de dezembro, - de proteção do Segredo Estatal, concretamente em relação a todos os documentos contendo dados e informações classificados - e no Decreto Presidencial 9/93, de 29 de dezembro, - que cria a Comissão Nacional para Implementação das Normas do Segredo do Estado - sua base de sustentação. Aliás, é com base nestes dois instrumentos legais que surge o Classificador de Informações, anexo ao Decreto n. ${ }^{\circ} 36 / 2007$, com o objetivo de implementar as Normas do Segredo do Estado na área dos arquivos, através do Serviço de Informações e Segurança do Estado, uma das quatro Sub-Comissões da Comissão Nacional para Implementação das Normas do Segredo do Estado. 
Portanto, não há nenhum cruzamento entre a classificação arquivística voltada para a organização de documentos e a classificação das informações em sua dimensão que funda o sigilo, nem se estabelece nenhum critério ou orientação metodológica no âmbito profissional inerente à gestão arquivística, muito menos do ponto de vista do acesso à informação para o cidadão comum, que facilmente pode se confundir. É nesse contexto que a Lei do Direito à Informação de Moçambique se afigura como espaço privilegiado de análise sobre matéria específica de classificação arquivística e sua relação com a classificação das informações, sobretudo, considerando o parágrafo n. $^{\circ}$ um do artigo 10 da referida Lei, que afirma que "os poderes públicos devem manter os arquivos disponíveis, salvo as exceções previstas por lei”, É nosso entendimento, no entanto, que manter o arquivo disponível significa a necessidade de sua organização, remetendo, obviamente, à classifcação arquivística. Contudo, num cenário como o de Moçambique em que não se pode falar de governança arquivística e no qual falta clareza e objetividade em relação à atividade classificatória, resulta numa interpretação de que a organização de arquivos constitui uma mera "arrumação de papeis" desprovida de critérios no âmbito da gestão arquivística e de princípios que salvaguardem o contexto de produção dos documentos de arquivo.

E o parágrafo número dois, do mesmo artigo estabelece que "Toda a informação deve ser mantida em registos devidamente catalogados e indexados de forma a facilitar o direito à informação". A prevalência de termos como "catalogação" e "indexação" sobre o de classificação, no quadro da Lei do Direito à Informação, denuncia o afastamento da referida Lei em relação à informação arquivística necessária ao cidadão, numa estratégia que circunscreve a generalidade de informações, cujo tratamento, o recurso privilegiado é a catalogação e indexação, legitimando a divulgação da informação e não o acesso. Ora, em nosso entender, o acesso à informação arquivística prevalece como efetivo tanto na realização do direito à informação quanto do exercício dos direitos de cidadania, se comparado à divulgação de informações genéricas que interessa mais ao sujeito dessa ação. Portanto, não seria demais afirmar que estamos diante de uma confusão suscitada nos termos de uma desorganização organizada para confundir quem quer que seja, num contexto em que o exercício da cidadania ainda se revela um projeto em esboço em nível nacional. 


\section{Considerações finais}

Este estudo permitiu o mapeamento da situação arquivística moçambicana, a partir do cruzamento e inter-relacionamento entre a prática arquivística nas instituições da administração pública - com ênfase na classificação arquivística - e a classificação das informações no âmbito da legislação sobre o direito à informação, contrapondo o sigilo que tende a prevalecer, nesses processos, em relação ao acesso à informação refreado em todas as suas dimensões.

Como foi possível perceber ao longo da pesquisa, a classificação arquivística enquanto uma operação técnica que viabiliza a organização dos documentos não encontra enquadramento nas práticas desenvolvidas nas instituições da administração pública assim como no âmbito da legislação sobre o direito à informação em Moçambique. Nesta, todas as referências à classificação estão orientadas somente àquela classificação referente à atribuição de graus de sigilo desenhando, deste modo, um cenário no qual o cidadão, desprovido do acesso à informação primária - que fica refém da falta de mecanismos claros e de programas de gestão da informação, associada ao caráter absoluto ou independente do sigilo -, não pode controlar o Estado que, sob o feitiço próprio, também não controla a si mesmo.

Assim, enquanto não se transpor a barreira que concebe a prática arquivística - com enfoque na classificação arquivística - como um mero exercício mecânico que dispensa o protagonismo de profissionais arquivísticos qualificados, para toma-la dentro do seu escopo técnico-científico e profissional, a gestão de documentos não pode ser forjada e, consequentemente, o acesso à informação, subjugado pelo caráter absoluto do sigilo patente na legislação sobre o direito à informação, também não pode ser exercido.

Portanto, estamos diante de um cenário arquivístico nebuloso em que se torna impossível garantir o acesso de algo - informação - que não foi previamente organizado e do qual não se detém controle em sua dimensão como objeto de ação profissional. Ao contrário, uma ação efetiva, estruturada, contínua e regulada do exercício das atividades arquivísticas, com enquadramento técnico-científico e profissional da área e seus profissionais no sistema de carreiras e sua regulamentação, parece oportuna e profícua. 


\section{Referências}

ASSEMBLEIA NACIONAL (França). Declaração dos direitos do homem e do cidadão. França, 26 ago. 1789. Disponível em: http://hdl.handle.net/11067/4074. Acesso em: 28 set. 2020.

BERNARDES, Ieda Pimenta; DELATORRE, Hilda. Gestão documental aplicada. São Paulo: Arquivo Público do Estado de São Paulo, 2008.

CENTRO NACIONAL DE DOCUMENTAÇÃO E INFORMAÇÃO DE MOÇAMBIQUE (CEDIMO). Manual de procedimentos do sistema nacional de arquivos do estado. Maputo, CEDIMO, 2009.

INDOLFO, Ana Celeste. Gestão de documentos: uma renovação epistemológica no universo da Arquivologia. Arquivística.net, Rio de janeiro, v. 3, n. 2, p. 28-60, jul./dez. 2007. Disponível em: https://brapci.inf.br/index.php/res/v/50444. Acesso em: 19 set. 2020.

INDOLFO, Ana Celeste et al. Gestão de documentos: conceitos e procedimentos básicos. Rio de Janeiro: Arquivo Nacional, 1995.

JARDIM, José Maria. O conceito e a prática de gestão de documentos. Acervo, Rio de Janeiro, v. 2, n. 2, p. 35-42, dez. 1987.

LIMA, Marcia H. T. Figueiredo et al. Uma análise do estatuto princípio-epistemológico do direito à informação na lei de acesso à informação (lei 12527/2011). In: ENCONTRO NACIONAL DE PESQUISA EM CIÊNCIA DA INFORMAÇÃO, 13., 2012. Rio de Janeiro. Anais... Rio de Janeiro, UFF: ANCIB, 2012. Disponível em: http://repositorios.questoesemrede.uff.br/repositorios/handle/123456789/1081. Acesso em: 26 set. 2020.

MOÇAMBIQUE. Constituição (1990). Constituição da República de Moçambique. Boletim da República, Maputo, n. 44, de 2 de novembro de 1990. Série I.

MOÇAMBIQUE. Constituição (2004). Constituição da República de Moçambique. Boletim da República, $1^{\text {a }}$ Série, n. 51, de 22 de dezembro de 2004.

MOÇAMBIQUE. Decreto n. 33/92, de 26 de outubro de 1992. Institui o Sistema Nacional de Arquivos. Boletim da República, Maputo, n. 43, p. 1-3, 26 out. 1992. Série I.

MOÇAMBIQUE. Decreto n. 35/2015, de 31 de dezembro. Aprova o Regulamento da Lei n. ${ }^{\circ}$ 34/2014, de 31 de dezembro, Lei do Direito à Informação. Boletim da República, Maputo, n.104, 2015. Série I.

MOÇAMBIQUE. Decreto n. 36/2007, de 27 de agosto. Altera o Sistema Nacional de Arquivos criado pelo Decreto n. 33/92, de 26 de outubro, passando a denominar-se Sistema Nacional de Arquivos do Estado (SNAE). Boletim da República, Maputo, n. 34, p. 22-106, 27 ago. 2007. Série I.

MOÇAMBIQUE. Decreto n. 84/2018, de 26 de dezembro. Aprova a revisão do Sistema Nacional de Arquivos do Estado (SNAE) e revoga o Decreto n. 36/2007, de 27 de agosto. Boletim da República, Maputo, n. 252, p. 2-35, 26 dez. 2018. Série I. 
MOÇAMBIQUE. Decreto Presidencial n. 9/93, de 29 de dezembro. Cria a comissão nacional para implementação das normas do segredo do estado. Boletim da República, Maputo, n. 52, p. 1-2, 29 dez. 1993. Série I.

MOÇAMBIQUE. Lei n. 12/79, de 12 de dezembro. Protege o segredo do estado. Boletim da República, Maputo, n. 109, p. 330, 12 dez. 1979. Série I.

MOÇAMBIQUE. Lei 18/91, de 10 de agosto. Define os princípios que regem a atividade da imprensa e estabelece os direitos e deveres dos seus profissionais. Boletim da República, Maputo, n. 32, p. 10-18, 10 ago. 1991. Série I.

MOÇAMBIQUE. Lei n. 34/2014, de 31 de dezembro. Lei do direito à informação. Boletim da República, Maputo, n. 105, p. 33-37, 31 dez. 2014. Série I.

MOÇAMBIQUE. Resolução n. 46/2006, de 26 de dezembro. Aprova a estratégia para a gestão de documentos e arquivos do estado (EGDAE). Boletim da República, Maputo, n. 51, p. 122-127, 26 dez. 2006. Série I.

NHARRELUGA, Rafael Simone. O estado e a construção da ordem arquivística em Moçambique (1975-2010). 2014. Tese (Doutorado em História, Política e Bens Culturais) Programa de Pós-Graduação em História, política e bens culturais, CPDOC/FGV, Rio de Janeiro, 2014.

NHARRELUGA, Rafael Simone. O governo eletrónico em Moçambique: uma reflexão sobre políticas públicas de informação. 2006. Dissertação (Mestrado em Ciência da Informação) - Universidade Federal Fluminense, Niterói, 2006.

ORGANIZAÇÃO DAS NAÇÕES UNIDAS (ONU). Declaração universal dos direitos humanos, adotada e proclamada pela Assembleia Geral das Nações Unidas 10 dez. 1948. Disponível em: https://www.unicef.org/brazil/declaracao-universal-dos-direitos-humanos. Acesso em: 25 set. 2020.

PADILHA, T. S.; SPUDEIT, D. Plano de classificação de documentos: análise das metodologias utilizadas por instituições brasileiras. Revista Brasileira de Biblioteconomia e Documentação, São Paulo, v. 10, n. 2, p. 121-143, 30 out. 2014.

PAES, Marilena Leite. Arquivo: teoria e prática. Rio de Janeiro: Fundação Getúlio Vargas, 2004.

RODRIGUES, Ana Márcia L. A teoria dos arquivos e a gestão de documentos. Perspectivas em Ciência da Informação, Belo Horizonte, v. 11, n. 1, p. 102-117, abr. 2006.

SILVA, Armando B. Malheiro da et al. Arquivística: teoria e prática de uma Ciência de informação. Porto: Afrontamento, 1998. 